\title{
Apoio Matricial e Saúde Mental: relato das potencialidades e desafios no fazer do NASF por uma psicóloga em uma Residência Multiprofissional em Saúde da Família
}

\author{
Apoyo Matriarcal y Salud Mental: relato de \\ las potencialidades y desafíos en hacer el \\ NASF por una psicóloga en una Residencia \\ Multiprofesional en Salud de la Familia
}

\section{Nara Fróis de Oliveira Nogueira' ${ }^{1}$ (1) Cecília de Santana Mota 2 (1) Dhara Santana Teixeira ${ }^{3}$ (1)}

\author{
${ }^{1}$ Autora para correspondência. Universidade Federal do Recôncavo da Bahia, Fundação Estatal de Saúde da Família (Salvador). Bahia, Brasil. \\ nara-frois@hotmail.com \\ ${ }^{2-3}$ Fundação Estatal de Saúde da Família (Salvador). Bahia, Brasil. csmota27@yahoo.com.br, dharateixeira@gmail.com
}

\begin{abstract}
RESUMO | INTRODUÇÃO: Uma das principais ferramentas do NASF$A B$ é o Apoio Matricial (AM), sendo uma estratégia de organização do trabalho, buscando a integração de equipes de referência e equipe especializada. Por ser uma estratégia essencial para o desenvolvimento de um cuidado integral é que temáticas como a Saúde Mental têm sido incluídas nas ações desenvolvidas na AB. Nesse sentido, o apoio matricial em saúde mental deve propiciar que os profissionais de referência possam qualificar a produção de cuidado em SM. OBJETIVO: Refletir sobre as potencialidades e desafios vivenciados na prática de apoio matricial em saúde mental na $A B$ a partir da experiência de uma psicóloga do NASF em uma Residência Multiprofissional em Saúde. METODOLOGIA: A prática descrita neste artigo refere-se a um estudo qualitativo, do tipo relato de experiência, onde buscou-se refletir sobre as atividades desenvolvidas ao longo do período de dois anos em uma Residência Multiprofissional em Saúde. Foram utilizados como fonte de dados escritos em portfólios e diários de campo da autora. RESULTADOS: Foram desenvolvidas ações que propiciaram a aproximação entre a equipe com as discussões relacionadas a Luta Antimanicomial, consultas compartilhadas e construção de PTS. Ao longo do processo de trabalho foi interessante perceber a apropriação dos profissionais na equipe de referência na condução das ações em saúde mental, demonstrando o papel essencial do AM para efetivar a clínica ampliada. CONCLUSÃO: O percurso traçado neste relato permite refletir sobre a importância de se estender e consolidar o cuidado em saúde mental na $A B$, promovendo mudanças importantes na lógica de atenção.
\end{abstract}

PALAVRAS-CHAVE: Estratégia de Saúde da Família. Saúde Mental. Atenção Básica. Política de saúde.
RESUMEN | INTRODUCCIÓN: Una de las principales herramientas del NASF-AB es el Apoyo Matriarcal (AM), siendo una estrategia de organización del trabajo, buscando la integración de equipos de referencia y equipo especializado. Por ser una estrategia esencial para el desarrollo de un cuidado integral es que temáticas como la Salud Mental han sigo añadidas en las acciones desarrolladas en la AB. En ese sentido, el apoyo matriarcal en salud mental debe propiciar que los profesionales de referencia puedan calificar la producción de cuidado en SM. OBJETIVO: Reflejar sobre las potencialidades y desafíos vividos en la práctica de apoyo matriarcal en salud mental en la $A B$ a partir de la experiencia de una psicóloga del NASF en una Residencia Multiprofesional en salud. METOdologíA: La práctica descripta en este artículo se refiere a un estudio cualitativo, del tipo relato de experiencia, donde se buscó reflejar acerca de las actividades desarrolladas a lo largo del periodo de dos años en una Residencia Multiprofesional en Salud. Fueron utilizados como fuente de datos, escritos en portafolios y diarios de campo de la autora. RESULTADOS: Fueron desarrolladas acciones que proporcionaron el acercamiento entre el equipo con las discusiones relacionadas a Lucha Antimanicomial, consultas compartidas y construcción de PTS. A lo largo del proceso de trabajo fue interesante percibir la apropiación de los profesionales en el equipo de referencia en el manejo de las acciones en salud mental demostrado el rol esencial del AM para efectivar la clínica ampliada. CONCLUSIóN: El camino delimitado en este relato permite reflejar sobre la importancia de extenderse y consolidar el cuidado en salud mental en la $\mathrm{AB}$, promoviendo cambios importantes en la lógica de atención.

PALABRAS CLAVE: Estrategia de Salud de la Familia. Salud Mental. Atención Básica. Política de salud. 


\section{Introdução}

A Estratégia de Saúde da Família (ESF), um dos pilares para consolidação dos princípios do Sistema Único de Saúde (SUS), tem como característica básica ser porta de entrada do sistema de saúde. Originalmente fundada a partir da noção de direito à saúde e equidade do cuidado, vem promovendo uma mudança significativa no modelo de atenção à saúde no Brasil. Dentro das possibilidades de atuação no âmbito da ESF está o Núcleo Ampliado de Saúde da Família e Atenção Básica (NASF-AB) (Ministério da Saúde, 2010).

Este configura-se como uma estratégia inovadora que tem por objetivo apoiar, ampliar e aperfeiçoar as ações desenvolvidas pela Atenção Básica (AB), contribuindo para a integralidade do cuidado aos usuários do SUS. O trabalho do NASF-AB deve auxiliar no aumento da capacidade de análise, intervenção e resolutividade sobre os problemas e necessidade de saúde do território, incluindo nesse escopo uma mudança na atitude e atuação dos profissionais da Saúde da Família (SF) e entre a própria equipe NASFAB (Ministério da Saúde, 2010).

O NASF-AB é constituído por equipes multiprofissionais, que de forma interdisciplinar devem atuar de maneira integrada com as equipes de Saúde da Família (eSF) nas quais está vinculada. É importante destacar que apesar de fazer parte dos serviços da Atenção Básica, o NASF-AB não se constitui como porta de entrada da Rede de Saúde, nem como serviço de especialidades na AB. Sendo assim, todas as ações desenvolvidas devem ser de responsabilidade compartilhada entre as equipes NASF-AB e eSF, visando à ampliação da clínica e mudança das práticas de cuidado (Ministério da Saúde, 2010).

Para compreender o processo de trabalho é necessário conceber que o NASF-AB constitui-se em retaguarda especializada para a Atenção Básica, desenvolvendo suas ações a partir de duas dimensões: clínico-assistencial, que se refere a atuação direta com os usuários, a partir dos atendimentos individuais, coletivos e comunitários; e técnico-pedagógi$\mathrm{ca}$, que produz ações de apoio matricial com e para as equipes de saúde (Ministério da Saúde, 2010).
É importante salientar que apesar da divisão didática dessas duas dimensões, elas podem e devem estar conectadas nos diversos momentos de atuação.

Neste contexto de $A B$ e NASF é que está situada a experiência relatada neste artigo. Sempre tive interesse na área da saúde, especificamente em políticas públicas de saúde, por esse motivo decidi ingressar na Residência Multiprofissional em Saúde da Família para me aproximar das temáticas pertinentes ao fazer saúde na atenção básica. Faz-se necessário situar a importância das experiências de Residência em Saúde no processo formativo de profissionais, tendo em vista que permitem um aprofundamento das práticas diante da intensa imersão em campo que as residências possibilitam, resultando em uma compreensão da saúde de forma integral, a partir de uma maior implicação política e ética nas ações desenvolvidas.

Os atravessamentos por todas as experiências vivenciadas ao longo dos dois anos da residência me fizeram refletir sobre quais algumas das possibilidades para desenvolver ações e dispositivos de apoio matricial em Saúde Mental na Atenção Básica? Essa pergunta norteará as experiências situadas no texto.

Foi no decorrer dessa experiência que eu aprendi sobre o conceito (e a prática) do apoio matricial (AM). De acordo com o Ministério da Saúde (2009), AM constitui uma das ferramentas fundamentais para a organização do processo de trabalho do NASF e aponta o núcleo como uma das principais estratégias de qualificação da atenção básica, utilizando os conceitos de Equipe de Referência e Equipe de Apoio Matricial.

O apoio matricial é uma estratégia de organização do trabalho em saúde que acontece a partir da integração de equipes de Saúde da Família envolvidas na atenção às demandas comuns de dado território com equipes ou profissionais de outros núcleos de conhecimento diferentes dos profissionais das equipes de AB (Ministério da Saúde, 2010). Sendo assim, o que se busca é assegurar a retaguarda especializada a equipes de referência, de maneira personalizada e interativa. 
A própria nomenclatura evidencia o papel do apoio matricial. O termo matricial se refere à matriz que pode significar, com base em sua origem latina, lugar de criação; ou ainda, fundamentado na sua utilização matemática, pode indicar um conjunto de números relacionados entre si e requerem análise na vertical, horizontal ou linhas transversais. A partir dessa definição, pode-se perceber que a escolha do termo serve para sinalizar a possibilidade da relação horizontal que deve ser mantida entre profissionais de referência e especialistas, contrapondo a rígida relação vertical fomentada pela tradicional estrutura dos sistemas de saúde. Já o primeiro termo - apoio - faz referência à forma como essa relação horizontal deve operar.

Sendo este, um pressuposto fundamental da proposta do NASF: a compreensão do que é conhecimento nuclear e do que é conhecimento comum e compartilhável entre a equipe de SF e o referido especialista. Por este motivo, o apoio matricial objetiva ampliar as possibilidades de realizar-se clínica ampliada e integração dialógica entre distintas especialidades e profissões, tendo em vista que nenhum especialista, de modo isolado, poderá assegurar uma abordagem integral (Campos \& Domitti, 2007).

Colocar o apoio matricial em prática nos serviços de saúde requer que algumas tarefas sejam realizadas, como por exemplo: 1) Explicitar e negociar atividades e objetivos prioritários; 2) definir claramente quem são os seus usuários; 3) avaliar a capacidade de articulação com as eSF e o trabalho em conjunto com elas; 4) identificar as possíveis corresponsabilidades e parcerias; 5) construir e acompanhar as atividades mediante indicadores de impacto (Ministério da Saúde, 2010).

O desenvolvimento do apoio matricial deve acontecer de acordo com a construção compartilhada de diretrizes clínicas e sanitárias entre os componentes de uma equipe de referência e os especialistas que oferecem apoio matricial. Essas diretrizes devem prever critérios para acionar o apoio e definir o espectro de responsabilidade tanto dos diferentes integrantes da equipe de referência quanto dos apoiadores matriciais, levando em consideração o grau de vulnerabilidade e risco existentes no território para estabelecer as estratégias de ações prioritárias, que devem ser realizadas em conjunto com as eSF e comunidade. Esse fazer busca romper com práticas de saúde engessadas que oferecem serviços à comunidade sem considerar qual a demanda existente, como parte de estratégias programáticas (Ministério da Saúde, 2010).

Na prática são alguns dos exemplos de possibilidades de atuação da equipe de apoio matricial, aqui entendidas nas equipes de NASF: (1) Atendimento compartilhado, para uma intervenção interdisciplinar, com troca de saberes, capacitação e responsabilidades mútuas, gerando experiência para ambos os profissionais envolvidos. (2) Intervenções específicas do profissional do NASF com os usuários e/ou famílias, com discussão e negociação a priori com os profissionais da equipe de Saúde da Família responsáveis pelo caso. (3) Ações comuns nos territórios de sua responsabilidade desenvolvidas de forma articulada com as equipes de Saúde da Família. Como o desenvolvimento do projeto de saúde no território, planejamentos, apoio aos grupos, trabalhos educativos, de inclusão social, enfrentamento da violência, articulação de rede intersetorial.

Por compreender a potência do apoio matricial para a consolidação de um sistema de saúde que desenvolva um cuidado integral é que essa proposta tem sido incentivada pelo Ministério da Saúde através de diversas políticas, como, por exemplo, as Políticas Nacionais de Saúde Mental, lançada em 2001; de Atenção Básica, em 2012; e de Humanização, em 2013 (Campos et al., 2014).

Nesta perspectiva, coadunando com a relevância do Apoio Matricial no fazer em saúde, no próximo tópico será abordado algumas das especificidades do apoio matricial em Saúde Mental, centrados principalmente no contexto de apoio na USF.

\section{Apoio matricial em saúde mental}

Diante da complexidade do fazer em saúde é necessário atentar de que existe um componente de sofrimento psíquico associado a maioria das situações de adoecimento. Sendo assim, é possível dizer que "todo problema de saúde é também de saúde mental e que toda saúde mental é também - e sempre - produção de saúde" (Ministério da Saúde, 2005, pp. 33). 
Neste contexto, nos últimos anos tem-se percebido um incentivo à promoção de ações de apoio matricial em Saúde Mental, tendo em vista que, em 2003, o Ministério da Saúde indicou o apoio matricial como diretriz para inclusão de ações de Saúde Mental da AB (Ministério da Saúde, 2003).

Com a criação do NASF-AB tem sido possível que a estratégia de apoio matricial seja realizada no próprio âmbito da $A B$, tendo especialistas que prestam esse apoio à equipe de referência. Destaca-se que as experiências de matriciamento em saúde mental na Atenção Básica são práticas pioneiras e consolidadas em todo o país (Ministério da Saúde, 2004; Tófoli \& Fortes, 2007).

Considerando que a Reforma Psiquiátrica aponta para a superação do modelo hospitalocêntrico/manicomial no atendimento aos usuários, tendo em vista um cuidado que não retire o sujeito do seu espaço social (Dimenstein et al., 2009), a Atenção Básica tem um importante papel no processo de reinserção social, já que está imersa nos territórios e é um espaço de produção de saúde, tanto para os usuários, quanto para suas famílias.

Desse modo, torna-se fundamental desenvolver estratégias que articulem a inserção da Saúde Mental na Atenção Básica, promovendo a interlocução entre os diferentes profissionais e serviços de saúde e qualificando as equipes de Saúde da Família para uma atenção ampliada em saúde que contemple a subjetividade e o conjunto de relações sociais que determinam desejos, interesses e necessidades (Figueiredo \& Campos, 2009).

Ainda segundo as autoras, o apoio matricial em saúde mental deve propiciar que os profissionais de referência possam qualificar a produção de cuidado em SM, buscando compreender as dimensões subjetiva e social do ser humano, mas que estejam acompanhados por outros profissionais especializados que desempenhem o papel de suporte para intervenção nesse campo.

Por esse motivo, é crescente a inserção do psicólogo na $A B$, como profissional da saúde mental, seja na própria ESF ou em equipes auxiliares como o NASF.
O psicólogo inserido na $A B$ é convocado a compartiIhar seus conhecimentos com todos os profissionais da área da saúde, independentemente de sua formação acadêmica, tendo em vista que a saúde mental é um tema transversal em qualquer prática de saúde, com a finalidade de possibilitar a qualificação da escuta e acolhimento do sofrimento psíquico dos usuários para promoção de uma clínica ampliada (Iglesias \& Avellar, 2016).

Ainda segundo os autores, esse novo modo de fazer não implica na perda da especificidade da psicologia, considerando que a mesma não transmitiria aos profissionais de referência as intervenções mais nucleares, mas atuaria para transmitir os conhecimentos indispensáveis à ampliação da resolutividade das demandas em saúde mental existentes no território.

Vale destacar que a inserção da Psicologia no SUS ocorreu a partir de tensionamentos entre dois aspectos: primeiro, a partir da inserção nos serviços como dispositivos para manutenção de uma lógica individualizante, tecnicista, biologizante. E segundo, como possibilidade de ruptura desse modelo hegemônico para o desenvolvimento de uma prática que amplie as possibilidades de modos de vida (Dimenstein \& Macedo, 2012).

Nesse sentido, é necessário estar atento ao desafio contínuo da atuação na $A B$ : a convocação para não se adequar a normatização das práticas. É a partir de um posicionamento político que o psicólogo na $A B$ deve intervir em um plano ético provocando análises nas políticas, nos processos de trabalho e nas relações que se estabelecem entre profissionais e usuários. É necessário que haja um compromisso com a reinvenção das práticas de atenção aos usuários, com a utilização de novas tecnologias de cuidado, alterando assim os modos de organização dos serviços (Dimenstein \& Macedo, 2012).

Por esse motivo, coloca-se como um dos objetivos deste texto procurar compreender qual o papel da psicologia como apoiador matricial em saúde mental na $A B$, pois compreendemos que o psicólogo da $A B$ pode contribuir neste trabalho compartilhando a abordagem da clínica psicossocial que considera o usuário como sujeito social, ao enfatizar sua subjetividade, corporalidade, historicidade na construção das ações em saúde. 
Diante de todas essas discussões, evidenciando que o fazer psi também se coletiviza e se compartilha na Atenção Básica, a partir da inserção da autora, enquanto residente de psicologia no NASF-AB, atuando de forma multiprofissional no apoio à Unidades de Saúde da Família, interessa-nos situar que o objetivo geral deste trabalho é refletir sobre as potencialidades e desafios vivenciados na prática de apoio matricial em saúde mental na $A B$, a partir da experiência de uma psicóloga do NASF em uma Residência Multiprofissional em Saúde.

Tendo o intuito a reafirmação da relevância do NASF, como importante dispositivo para garantir a integralidade das ações em saúde, a qualificação dos profissionais e um atendimento humanizado aos usuários. Tendo em vista que a diversidade de saberes que compõem o núcleo amplia a possibilidade de intervenção e cuidado, diversificando também a atuação para além de uma postura centrada na doença. Diante de todas essas vertentes a relevância desse trabalho se apresenta na contribuição que os conhecimentos sobre a prática do apoio matricial podem produzir nos profissionais de saúde e na produção do cuidado.

\section{Metodologia}

A prática descrita neste artigo refere-se a um estudo qualitativo, do tipo relato de experiência, onde buscou-se refletir sobre as atividades desenvolvidas ao longo do período de dois anos (2019-2021) em uma Residência Multiprofissional em Saúde da Família, no estado da Bahia.

O relato de experiência é um texto que descreve precisamente uma dada experiência que possa contribuir de forma relevante para sua área de atuação, está relacionada a uma vivência profissional tida como exitosa ou não, mas que contribua com a discussão, a troca e a proposição de ideias para a melhoria do cuidado na saúde (Gerhardt \& Silveira, 2009). É importante ressaltar que mesmo em se tratando de um relato de experiência e não uma pesquisa com seres humanos, o compromisso ético com os participantes do relato sobre o sigilo, a autonomia, a beneficência, a não maleficência - foram considerados neste relato.
Para compreender o campo que será descrito neste relato, cabe situar que as Residências Multiprofissionais em Saúde foram criadas a partir da promulgação da Lei no 11.129 de 2005 são orientadas pelos princípios e diretrizes do Sistema único de Saúde (SUS), e devem se organizar a partir das necessidades e realidades locais e regionais, abrangendo as profissões da área da saúde (Resolução CNS n 287/1998). São definidas como modalidade de ensino de pós-graduação lato sensu, voltada para a educação em serviço e destinada às categorias profissionais que integram a área de saúde, que tem por objetivo ser um programa de cooperação intersetorial para favorecer a inserção qualificada dos jovens profissionais da saúde no mercado de trabalho, particularmente em áreas prioritárias do Sistema Único de Saúde. (Ministério da Saúde, 2005).

O campo de atuação descrito neste relato é a Residência Multiprofissional em Saúde da Família (RMSF), orientado pela Fundação Estatal em Saúde da Família (FESF-SUS) em parceria com a Fundação Oswaldo Cruz (FIOCRUZ).

Os profissionais assumem o serviço desenvolvendo todas as atividades previstas para o Núcleo, buscando atingir competências e habilidades previstas no Projeto Político Pedagógico do Programa. Essa modalidade de atuação possibilita que o residente se reconheça como profissional da saúde e integrante da equipe proporcionando uma postura mais autônoma, tendo em vista que a transformação das práticas de cuidado em saúde está relacionada com as mudanças na postura profissional.

O campo de prática da Residência Multiprofissional em Saúde da Família é um município de médio porte localizado na Região Metropolitana de Salvador/ Bahia. Com população aproximada de 80 mil habitantes. O sistema municipal de saúde, especificamente na Atenção Básica, é composto por 19 equipes de Saúde da Família em 16 Unidades de Saúde da Família (incluindo zona rural e urbana) e 3 NASF, sendo um NASF composto por profissionais do município e dois por profissionais residentes.

Cada NASF da Residência apoia 5 eSF em 4 USF, uma delas na zona rural do município. A equipe de NASF é composta por dois psicólogos, uma nutricionista, duas fisioterapeutas, um professor de educação física e atualmente conta com preceptoria de uma professora de educação física. 
As atividades desenvolvidas pela equipe NASF foram as mais diversas: atendimentos individuais e compartilhados com a eSF e com o próprio NASF, criação e condução de grupos e atividades coletivas, momentos de educação permanente, articulação de rede de saúde e intersetorial, mapeamento dos equipamentos sociais do território, visitas domiciliares, organização e participação em Feiras de Saúde, criação e consolidação de hortas comunitárias, participação em projetos de Farmácia Viva para plantio de fitoterápicos, atividades do Programa Saúde na Escola, participação em reuniões comunitárias.

Para sistematização deste relato foram utilizados os registros realizados durante o período de vigência da residência: os relatos no portfólio, que é uma ferramenta da RMSF-FESF para registro e análise individual da prática desenvolvida. Bem como escritos pessoais da autora, como diários de campo.

A seguir, discutiremos mais detalhadamente algumas das ações desenvolvidas pelos psicólogos da equipe NASF buscando realizar a articulação entre o fazer do NASF, a partir da perspectiva do apoio matricial, e as aproximações com a Saúde Mental na Atenção Básica.

\section{Resultados e discussão}

Descrever, analisar e refletir sobre as práticas desenvolvidas durante o período de residência requer um movimento inicial de situar o leitor no contexto de inserção em um campo cercado de atravessamentos. Como discutido anteriormente, o papel do NASF como referência para o apoio matricial é de um lugar de ruptura com o modelo hegemônico vigente nas práticas e na formação em saúde. Portanto, antes de iniciar o relato é necessário contar o movimento de desconstrução da profissional psicóloga para inserção no NASF e compreensão do apoio matricial.

Historicamente a constituição da Psicologia como ciência e profissão foi utilizada como dispositivo de controle e governo dos corpos e da vida. Com uma prática liberal, caracterizada pelo elitismo, individualismo e patologização da vida, manteve-se distante das necessidades da maior parcela da população (Cela \& Oliveira, 2015).
Ainda segundo as autoras, é desse modo que as formações em Psicologia estruturam suas grades curriculares. As técnicas, os instrumentos, as linguagens e os valores da Psicologia foram forjados para atender as demandas de um grupo com renda média, e seriam agora transpostas a uma parcela da população cuja realidade social é desconhecida dessa Psicologia tradicional, o que ocasiona a formação de profissionais pouco preparados para uma atuação multiprofissional, interdisciplinar e pautados em uma clínica ampliada.

Sair das certezas que a formação tradicional oferece não é tarefa fácil e nem ocorre sem crises. Não ter um lugar seguro onde se apoiar gera dúvidas, angústias e medos. Por esse motivo, faz-se necessário situar a característica da formação, pois a minha inserção enquanto residente na equipe de NASF trouxe muitas angústias e incertezas acerca do trabalho a ser realizado. Por se tratar de um campo novo, que representa uma ruptura no modelo de atenção, e por ter uma demanda reprimida muito grande no campo de práticas.

A inserção do psicólogo na AB possibilita a ampliação do olhar sobre as questões de saúde, mas coloca o profissional diante de desafios que precisam ser superados cotidianamente. Um deles é a compreensão de qual a representação que essa categoria profissional tem para os outros profissionais e para a comunidade. É necessário desconstruir a imagem de que as questões relacionadas à Saúde Mental têm sempre uma resposta ou uma intervenção pronta. Para superar esse desafio é necessário reconhecer e ampliar as possibilidades de atuação da Psicologia e que haja um movimento de análise constante das práticas desenvolvidas (Cezar et al., 2015).

Por esse motivo, Nascimento et al. (2006) orientam quanto a importância da ruptura da identidade profissional como um método constante. Colocar em análise o lugar que ocupamos, nossas práticas de saber-poder enquanto produtores de verdades consideradas absolutas, universais e eternas - bem como, os efeitos que produzem, com o que se agenciam. Essa perspectiva rompe com a lógica racionalista e afirma que "toda e qualquer prática perpetrada é sempre implicada, produz efeitos, é sempre política" (pp. 17). 
O desafio está na realização de um trabalho mais ampliado e não focado no modelo clínico individual ou nas ações exclusivas de saúde mental. Para tanto, o campo requer uma flexibilidade para trabaIhar em equipe, com vistas a superar a fragmentação do conhecimento focado nas especialidades, por meio de uma relação mais aberta com as equipes de saúde.

Além do desafio apontado acima, outra dificuldade encontrada foi o desenvolvimento de um trabalho mais integrado com as equipes da ESF. Em muitas situações foi difícil discutir casos e compartilhar intervenções, tendo em vista que alguns profissionais acreditavam que as ações de saúde mental eram de responsabilidade exclusiva das psicólogas. Ademais, persiste o desafio de tornar as ações de prevenção, promoção e educação em saúde em práticas cotidianas nas equipes de ESF. Essas intervenções ainda ocorrem de maneira pontual e por meio de iniciativas de alguns profissionais (Cezar et al., 2015).

A aposta nesse modo de produção de cuidado e a tentativa diária de superação desses desafios ocorre por conta da compreensão de que a $A B$ tem um volume de possibilidades e potencialidades capazes de ir além do atendimento à doença, o que torna cada vez mais possível acreditar em ações de saúde mental que visem à promoção de um cuidado integral.

\section{Desenvolvimento das práticas}

Todos os aspectos discutidos até aqui serão descritos a partir da escolha de três intervenções realizadas ao longo do período da residência e que representam as potencialidades e os desafios diante do fazer do NASF na função de apoio matricial.

\section{Aproximação entre Luta Antimanicomial e Saúde da Família}

Compreendendo a relevância de compartilhar os saberes e novas práticas advindas da Reforma Psiquiátrica, e considerando o mês de maio (especificamente o dia 18 de Maio) como período de maior engajamento nas questões concernentes a Luta Antimanicomial foram desenvolvidas atividades de matriciamento entre equipe NASF, eSF e salas de esperas nas Unidades de Saúde para aproximação com a temática.

Em momentos de Educação Permanente nas reuniões de NASF-AB, foram explicitados aos demais profissionais a História e os Princípios da Reforma Psiquiátrica, e as rupturas que se propõe em relação ao modelo manicomial, no intuito de aproximar as outras categorias profissionais que compunham a equipe com a temática, bem como planejar as ações que viriam a ser desenvolvidas.

Foi possível notar o quanto as discussões sobre a Reforma Psiquiátrica ainda são desconhecidas pelos profissionais de saúde. Muitos relataram que não tinham informações suficientes sobre o movimento, sobre a data e sobre as especificidades que a Reforma proporciona ao cuidado em Saúde Mental; alguns ainda entendiam o cuidado a partir do modelo manicomial como principal possibilidade de cuidado plausível. Por exemplo, alguns profissionais durante as reuniões falavam sobre o medo e a associação que se estabelece entre loucura e periculosidade, remetendo-a unicamente a episódios de crise aguda, marcada por agressividade e/ou impulsividade.

Desse modo, falar sobre a associação entre loucura e periculosidade é falar sobre a produção social do medo. O medo não se refere unicamente a um fenômeno psicológico, mas histórico e social também (Cunha, 2016). A lógica manicomial, calcada nos ideais de exclusão e estigmatização, tem na associação entre loucura e periculosidade um de seus pilares de manutenção. A ideia de periculosidade surge associada ao conceito da loucura, por esta em nossa sociedade ser vista como perda de razão, estranheza, ausência de individualidade e subjetividade.

Em nome deste perigo e, para garantir a ordem social, o louco teve seus direitos civis, sociais e políticos negados e sua liberdade sequestrada. A trajetória de intolerância e preconceito ligada ao louco fez do hospital psiquiátrico o emblema da exclusão e do sequestro da cidadania e, da vida dos sujeitos, um sofrimento (Rossi, 2015). Temer a loucura serve apenas para justificar a violência que se emprega contra o louco e para validar o distanciamento e estigmatização da loucura na sociedade. Ancorados no discurso do medo pode-se "ajudar", diagnosticar, "tratar", das mais variadas e violentas formas, sem nenhuma garantia de um devido acesso à saúde. 
Após essas discussões, perceber o reconhecimento dos profissionais e a abertura para a dissociação entre loucura e periculosidade, bem como para o reconhecimento do quanto as práticas desenvolvidas na saúde ainda reproduzem discursos manicomiais constituíram-se como um início promissor do trabaIho que foi desenvolvido.

E isso fica nítido no momento de realização das ações planejadas. Os profissionais do NASF, de todas as categorias, se envolveram no planejamento e desenvolvimento das ações com engajamento e propriedade. Uma dessas ações foi uma Sala de Espera para os usuários da USF.

Antes, é importante destacar a relevância da estratégia das Salas de Espera para a aproximação entre usuários, profissionais e temas concernentes à Saúde. Ela é um espaço estratégico que pode ser utilizado para potencializar as ações de educação, constituindo-se um espaço de trocas de experiências e compartilhamento de histórias de vida, reflexão e construção de novos sentidos sobre si mesmo, sobre o outro e suas vidas, promovendo um trabalho multiprofissional e interdisciplinar (Pedrosa \& Pereira, 2020).

Em uma dramatização, uma profissional interpretou uma pessoa em sofrimento psíquico em um contexto manicomial, com o intuito de suscitar a discussão sobre o cuidado em liberdade e a abolição de práticas manicomiais. Foi interessante notar o quanto os profissionais, ditos "não psis", se apropriaram da discussão e levantaram questões extremamente pertinentes no diálogo com os usuários, o que reforça a potência do matriciamento.

A compreensão e apropriação com as temáticas relacionadas à Saúde Mental possibilitam que os profissionais desenvolvam certo nível de criticidade e rompimento com os estigmas, permitindo maior aproximação aos casos, diminuindo o sentimento de medo dos profissionais e facilitando assumir a responsabilidade sanitária da equipe sobre os casos (Amaral et al., 2018). Ao aumentar a capacidade das equipes da ESF em lidar com o sofrimento psíquico e integrá-las com os demais pontos da rede assistencial, o apoio matricial progressivamente fortalece o cuidado em saúde mental enquanto demanda legítima da AB.

\section{Compartilhamento do cuidado nas consultas}

Ao longo do período de inserção nas atividades do NASF, uma das bases do trabalho desenvolvido eram as consultas compartilhadas com outros profissionais de saúde, tanto do NASF, quanto da eSF.

Em uma das consultas desenvolvidas, de acompanhamento de pré-natal, várias demandas de Saúde Mental emergiram, desde questões de histórico psiquiátrico e, portanto, fator de risco para depressão pós-parto (Arrais et al., 2018) à não aceitação da gestação. A profissional que acompanhei sinalizou que nunca tinha visto tantas demandas em SM em um único momento. Ou seja, as demandas existem, mas falta predisposição ou acolhimento suficientes para encontrá-las e, sobretudo, dar os encaminhamentos necessários. O que nos faz refletir que se não houvesse a minha participação, desenvolvendo a função de apoiador matricial, todas essas questões seriam invisibilizadas.

Por esse motivo, os atendimentos conjuntos com o profissional matricial têm uma importante função pedagógica, já que as equipes podem aprender in loco a intervir no campo da Saúde Mental e se autorizar nas ações que nem sempre cabem nos protocolos, lidando com situações de exclusão social, violência, luto e que podem ser acolhidas durante a própria consulta clínica. Ou ainda, quando os profissionais referem se sentir inseguros para lidar com pacientes psicóticos ou com quadros psiquiátricos mais graves e o atendimento conjunto com o apoiador matricial pode proporcionar um encontro desmistificador do sofrimento psíquico e da doença mental, ajudando a diminuir o preconceito e a segregação da loucura (Amaral et al., 2018).

Após as consultas compartilhadas, a profissional que acompanhei sinalizou a importância das trocas interdisciplinares e o quanto conseguiu complexificar sua visão dos casos e possibilidades de intervenção. $\mathrm{Na}$ prática do Apoio Matricial esse é um dos objetivos a serem alcançados, proporcionar que os profissionais da equipe de referência possam ampliar as próprias práticas, exercitar a escuta qualificada, realizar acompanhamento sistemático de alguns casos, possibilitando a organização da assistência de modo que o usuário que necessita de atenção em saúde mental possa ter um acompanhamento resolutivo e integral. 
Além disso, pretende-se, com isso, produzir co-responsabilização entre Equipe de Referência e profissionais matriciais, com a possibilidade de garantia de encontro produtivo entre equipes da Atenção Básica e equipes dos CAPS, com vistas à ampliação do cuidado em saúde mental (Iglesias \& Avellar, 2019).

Da interação do apoiador matricial com o profissional de referência, um afetando e sendo afetado pelo outro, compartilhando conhecimentos, experiências, visões de mundo, consonâncias e dissonâncias inclusive, emergem novas perspectivas, possibilidades produtivas e relações interpessoais. A riqueza desse processo diz respeito às intervenções ocorrerem não somente na vida dos usuários, mas, também, nos profissionais. O processo implica a construção do trabalho em ato, na escuta e no compartilhamento de informações, na planificação de um projeto terapêutico singular e na corresponsabilização dos profissionais envolvidos (Hirdes, 2015).

\section{Construção de Projeto Terapêutico Singular}

O Projeto Terapêutico Singular (PTS) é uma das ferramentas de trabalho no cuidado desenvolvido pela $A B$, ele é compreendido como um conjunto de propostas de condutas terapêuticas construídas com e para um sujeito individual ou coletivo. Geralmente dedicada a casos complexos, ele é uma variação da discussão de caso (Ministério da Saúde, 2009). Nele as equipes de referência e apoio matricial podem organizar um plano de cuidado junto com os(as) usuários(as) e suas famílias com o objetivo de facilitar a realização das intervenções necessárias que alcancem um cuidado integral, resolutivo para as demandas existentes.

Nesse sentido, foram desenvolvidos alguns PTS para casos complexos de Saúde Mental que deveriam envolver todos os profissionais. Inicialmente foram organizados alguns momentos de educação permanente, nas reuniões, para apresentar às equipes o que é e como funciona o PTS. Após essa primeira aproximação com a temática, a equipe elegeu casos que foram discutidos de forma geral nas reuniões de eSF, os mais complexos que demandavam um cuidado intensificado foram escolhidos, bem como os profissionais de referência para o caso. As intervenções foram organizadas no PTS a partir dos seguintes momentos: diagnóstico, definição de metas, divisão de responsabilidades e reavaliação (Ministério da Saúde, 2009).
Após a escolha dos casos, foram marcados encontros com os usuários para levantamento das metas, intervenções e os prazos para as mesmas. Essa é uma etapa essencial da construção do PTS, tendo em vista que o mesmo deve constituir-se como uma proposta terapêutica pactuada com o usuário. É com amparo no singular de cada sujeito explicitada no PTS que os trabalhadores de saúde podem promover uma relação dialógica e interativa com o usuário, centrando-se em suas pretensões, suas experiências de vida e de seu processo saúde-doença, opiniões e necessidades (Jorge et al., 2015).

Os encontros para realização das intervenções pactuadas eram realizados com periodicidade definida com os usuários, que variavam entre encontros semanais, quinzenais e mensais, com a participação dos profissionais responsáveis pelo caso e outros, caso fosse necessário. Os primeiros encontros eram dedicados à vinculação com o usuário, compreensão do seu contexto, levantamento da história de vida e estado de saúde. Feitos com muito cuidado, esses encontros foram essenciais para a continuação do trabalho desenvolvido, pois aproximava o usuário de nós, estimulando a corresponsabilidade com o andamento das ações e uma interação horizontal.

Diante da complexidade dos casos, diversas intervenções foram pensadas e colocadas em prática: início de acompanhamento com odontólogo, fisioterapeuta, nutricionista, entre outros profissionais; acompanhamento terapêutico; atividades de arte; inserção em grupos; articulação com os serviços da atenção especializada; entre outros.

À medida que as ações eram desenvolvidas, reuniões periódicas entre os profissionais eram realizadas para discussão, avaliação das intervenções e tomada de decisões para os próximos passos. Sendo este um dos aspectos relevantes do PTS como ferramenta para o apoio matricial, sua construção exige que o caso seja discutido constantemente entre os profissionais de referência. O PTS implica em compartilhamento de percepções e reflexões entre profissionais de diferentes áreas do conhecimento, através da divisão de tarefas e responsabilização compartilhada, na busca pela compreensão da situação ou problema em questão (Silva et al., 2019). 
O PTS é considerado uma ferramenta para disparar processos de mudanças nas práticas de saúde, pois possibilita uma maior aproximação entre os profissionais e as demandas em Saúde Mental. Sendo, portanto, um excelente espaço de formação permanente. Por outro lado, é um espaço de troca e de aprendizado para os apoiadores matriciais, que também experimentarão aplicar seus saberes em uma condição complexa, recheada de variáveis com as quais nem sempre o recorte de uma especialidade está acostumado a lidar. (França et al., 2020; Brasil, 2009). Por necessariamente ser uma construção coletiva, o projeto terapêutico incorpora a noção interdisciplinar e/ou transdisciplinar que partindo dessa atitude integrativa entre os profissionais possibilita não apenas a troca de saberes, mas na prática inter/ transdisciplinar "não se ensina, nem se aprende: vivese, exerce-se" (Cela \& Oliveira, 2015, p. 34).

Essa noção é extremamente importante para podermos pensar nos modos de práticas de saúde a partir do conceito de transdisciplinaridade. Nesse sentido, a transdisciplinaridade surge como um dispositivo a partir da compreensão de que a complexidade evidenciada nos casos acompanhados pelos serviços de saúde não permite a realização de um fazer clínico que seja individualizado. Transdisciplinar, porque os conhecimentos que fazem parte dela devem ser tão interligados, que no entrelaçamento entre eles haja transformação um do outro e não necessite haver distinções entre si. Isso nos tira do lugar de especialista, pois nenhum saber nunca será suficiente para dar conta do plano da realidade de cada sujeito (Ministério da Saúde, 2009).

Ao longo do processo de construção foi interessante perceber a apropriação com a qual os profissionais na equipe de referência passaram a conduzir as ações, envolvidos - inclusive afetivamente - com os casos, eles passaram assumir a responsabilidade das atividades desenvolvidas com os usuários que anteriormente seriam tachados como "de saúde mental" e encaminhados de forma indiscriminada.
Vale destacar que só é possível desenvolver um trabalho transdisciplinar se o cuidado for desenvolvido em rede. As experiências descritas tornam nítida a importância da construção de redes vivas de cuidado que coloquem em conexão os vários serviços existentes nos territórios, produzindo o encontro de trabalhadores e usuários, com potência para elaborar e executar projetos terapêuticos singulares, sendo este um dos objetivos centrais e um dos maiores desafios do apoio matricial. Requer ir além da estruturação da rede física dos serviços, e considerar a dinâmica micropolítica da rede de cuidados, que desafia os espaços de gestão do SUS e pede um olhar singular (방 \& Nascimento, 2014).

Todas as articulações citadas acima criam a possibilidade de efetivar a tão almejada clínica ampliada, cuja função, por excelência, seria acompanhar movimentos, metamorfoses subjetivas, paisagens que vão se processando cotidianamente na vida, proporcionando um meio criador para encontros e composições. Uma clínica como prática política que tem a ver com afeto e com a fabricação de modos de existência (Dimenstein et al., 2009). Como nos apresenta Passos e Benevides (2000) a clínica enquanto experiência de desvio, que faz bifurcar um percurso de vida na criação de novos territórios existenciais, que implica em uma atitude de acolhimento de quem demanda tratamento.

Dessa forma, existe a possibilidade de incorporar o cuidado em saúde mental numa perspectiva de clínica ampliada, mediante uma abordagem interdisciplinar e/ou transdisciplinar. $\mathrm{O}$ apoio matricial em saúde mental implica que essa construção coletiva do trabalho ocorra como um processo. Assim, o apoio matricial gera possibilidades de "maiores coeficientes de transversalidade nas relações entre os profissionais das equipes de referência, entre equipes de vários serviços e entre estes e os profissionais de áreas especializadas" (Hirdes \& Scarparo, 2015, pp. 389). 
A ampliação do espaço das práticas em saúde mental na $A B$, como no NASF, por exemplo, contribui para a crítica e a desconstrução dos artifícios técnicos nas práticas hegemônicas. Isto porque a ampliação da clínica só será possível na reorganização do conhecimento, mediante um amplo processo de capacitação das equipes para lidarem com a subjetividade e uma reorganização dos modos de como se trabalha, que permita a construção de vínculo (Hirdes \& Scarparo, 2015).

O processo da reforma psiquiátrica convida a todos os profissionais e serviços a repensarem o seu fazer em saúde mental, numa lógica de cuidado que promova a desinstitucionalização, a valorização da fala do sujeito e a superação da atenção centrada na medicalização, para assim poder pensar em processos terapêuticos que possam produzir a reinserção social desses usuários. A partir disso, o paradigma manicomial vem sendo desconstruído, gerando novas demandas para o pensar e o fazer desses profissionais.

Todos os aspectos elencados até aqui destacam alguns elementos que são imprescindíveis para o desenvolvimento do apoio matricial em saúde mental, são eles: transdisciplinaridade, rede de relações, integralidade, autonomia do sujeito em seu processo de subjetivação, intersetorialidade, formação de vínculo, humanização e por fim, implicação e análise (produção) de nós mesmos.

\section{Considerações finais}

A inserção do NASF na $A B$ permite que pequenas alterações nas práticas de saúde possibilitem ações com um olhar voltado para a complexidade da vida dos sujeitos e suas necessidades de saúde. Essa nova perspectiva, um tanto quanto revolucionária, demanda que essas ações sejam realizadas a partir de um trabalho conjunto, transdisciplinar, tornando o apoio matricial um importante dispositivo para a ampliação da clínica.

No que tange ao apoio matricial em saúde mental é possível refletir sobre a importância de se estender e consolidar o cuidado em saúde mental na $A B$, promovendo mudanças importantes na lógica de atenção.
A saúde mental precisa ser vista como um campo plural e integrado às diversas linhas de cuidado das equipes de Atenção Básica/Saúde da Família.

Alguns desafios ainda precisam ser superados e as equipes precisam estar cientes de suas responsabilidades como equipe de referência diante dos casos de saúde mental, todavia o caminho vem sendo construído, ainda que a passos lentos. De todo modo, acredito que o trabalho de apoio matricial relatado neste artigo possibilitou agregar saberes e instaurar reflexões positivas no sentido de desfazer os 'nós' da desinstitucionalização, estabelecer laços longitudinais e fortalecer o olhar das equipes de saúde da família e do próprio NASF para o território no que tange às demandas de saúde mental.

Todo o trajeto traçado aqui oportuniza a reflexão de que a organização e a prática da assistência em saúde pautadas no apoio matricial possibilitam um fazer que busca desvios e inventa caminhos nunca imaginados, imprimindo análises a partir de um conjunto de diferentes lógicas, recusando o lugar da solução de problemas imediatos e atuando no inusitado dos acontecimentos (Nascimento et al., 2006).

Para finalizar, é imprescindível que se faça uma análise para as tentativas de retrocesso que as políticas públicas de saúde têm sofrido ao longo dos últimos anos. Os avanços admitidos através da luta coletiva de trabalhadores, usuários e gestores do SUS em prol da defesa e operacionalização de um sistema de saúde equânime, universal e integral estão sendo atingidos por aqueles que acreditam que saúde é mercadoria.

Tanto as políticas de Atenção Básica quanto às políticas de Saúde Mental (bases para o fazer no NASF) estão sofrendo desmontes com a instituição de direcionamentos para o trabalho que não coadunam com os princípios da Reforma Psiquiátrica e da Reforma Sanitária. Por esse motivo é a partir da dimensão ético-política que deve estar presente em nosso fazer, que uma ação atuante e militante deve ser feita. Defender o SUS, defender as reformas, defender o NASF, defender o apoio matricial e a clínica ampliada como práticas de cuidado são ferramentas importantes para a manutenção de um fazer em saúde para todas, todes e todos. 


\section{Contribuições das autoras}

Nogueira FON participou da concepção do relato, produção e redação do manuscrito, incluindo a discussão, revisão e aprovação da versão final do artigo. Mota CS e Teixeira DS contribuíram substancialmente em todas as etapas da concepção e elaboração do artigo, incluindo a discussão dos dados, revisão e aprovação da versão final do artigo.

\section{Conflitos de interesses}

Nenhum conflito financeiro, legal ou político envolvendo terceiros (governo, empresas e fundações privadas, etc.) foi declarado para nenhum aspecto do trabalho submetido (incluindo, mas não se limitando a subvenções e financiamentos, participação em conselho consultivo, desenho de estudo, preparação de manuscrito, análise estatística, etc.).

\section{Referências}

Amaral, C. E. M., Torrenté, M. D. O. N. D., Torrenté, M. D., \& Moreira, C. P. (2018) Apoio matricial em Saúde Mental na atenção básica: efeitos na compreensão e manejo por parte de agentes comunitários de saúde. Interface Comunicação, Saúde, Educação, 22(66), 801-812. https://doi. org/10.1590/1807-57622017.0473

Arrais, A. R, Araújo, T. C. C. F., \& Schiavo, R. A. (2018). Fatores de Risco e Proteção Associados à Depressão Pós-Parto no Pré-Natal Psicológico. Psicologia: Ciência e Profissão, 38(4), 711-729. https://doi.org/10.1590/1982-3703003342016

Campos, G. W. S., \& Domitti, A. C. (2007). Apoio matricial e equipe de referência: uma metodologia para gestão do trabalho interdisciplinar em saúde. Cadernos de saúde pública, 23 (2), 399-407. https://doi.org/10.1590/S0102311X2007000200016

Campos G. W. S., Figueiredo M.D., Pereira Júnior N., \& Castro C. P. (2014). A aplicação da metodologia Paideia no apoio institucional, no apoio matricial e na clínica ampliada. Interface - Comunicação, Saúde, Educação, 18(Supl 1), 98395. https://doi.org/10.1590/1807-57622013.0324
Cela, M., \& Oliveira, I. F. (2015). O psicólogo no Núcleo de Apoio à saúde da Família: articulação de saberes e ações. Estudos de Psicologia (Natal), 20(1). https://doi.org/10.5935/1678$\underline{4669.20150005}$

Cezar, P. K., Rodrigues, P. M., \& Arpini, D. M. (2015). A Psicologia na Estratégia de Saúde da Família: Vivências da Residência Multiprofissional. Psicologia: ciência e profissão, 35(1), 211224. http://dx.doi.org/10.1590/1982-3703000012014

Cunha, T. C. (2016). De que(m) temos medo? A produção social do medo como discurso de ordem. Revista Mythos. https:// www.academia.edu/download/53397342/De quem temos_medo_- Thiago_Colmenero_Cunha_-_revista_ Mythos_maio2017.pdf

Dimenstein, M., Severo, A. K., Brito, M., Pimenta, A. L., Medeiros, V., \& Bezerra, E. (2009). O apoio matricial em Unidades de Saúde da Família: experimentando inovações em saúde mental. Saúde e sociedade, 18(1), 63-74. https://doi. org/10.1590/S0104-12902009000100007

Dimenstein, M., \& Macedo, J. P. (2012). Formação em Psicologia: requisitos para atuação na atenção primária e psicossocial. Psicologia: Ciência e Profissão, 32(SPE), 232245. https://doi.org/10.1590/S1414-98932012000500017

Figueiredo, M. D., \& Campos, R. O. (2009). Saúde Mental na atenção básica à saúde de Campinas, SP: uma rede ou um emaranhado? Ciência \& Saúde Coletiva, 14(1), 129-138. https://doi.org/10.1590/S1413-81232009000100018

França, M. A. S. A., Spirandelli, A. C. M. A., \& Verde, M. C. C. L. V. (2020). Uso de ferramentas de gestão na micropolítica do trabalho em saúde: um relato de experiência. Saúde em Debate, 43(6), 138-146. https://doi.org/10.1590/0103110420195613

Hirdes, A. (2015). A perspectiva dos profissionais da Atenção Primária à Saúde sobre o apoio matricial em saúde mental. Ciência \& Saúde Coletiva, 20(2), 371-382. https:// doi.org/10.1590/1413-81232015202.11122014

Hirdes, A., \& Scarparo, H. B. K. (2015). O labirinto e o minotauro: saúde mental na Atenção Primária à Saúde. Ciência \& Saúde Coletiva, 20(2), 383-393. https://doi. org/10.1590/1413-81232015202.12642013 
Hori, A. A., \& Nascimento, A. F. (2014). O Projeto Terapêutico Singular e as práticas de saúde mental nos Núcleos de Apoio à Saúde da Família (NASF) em Guarulhos (SP), Brasil. Ciência \& Saúde Coletiva, 19(8), 3561-3571. https://doi. org/10.1590/1413-81232014198.11412013

Iglesias, A., \& Avellar, L. Z. (2016). As contribuições dos psicólogos para o matriciamento em saúde mental. Psicologia: Ciência e Profissão, 36(2), 364-379. https://doi.org/10.1590/19823703001372014.

Iglesias, A., \& Avellar, L. Z. (2019). Matriciamento em Saúde Mental: práticas e concepções trazidas por equipes de referência, matriciadores e gestores. Ciência \& Saúde Coletiva, 24(4), 1247-1254. https://doi.org/10.1590/1413$\underline{81232018244.05362017}$

Gerhardt, T. E., \& Silveira, D. T. (2009). Métodos de pesquisa. Plageder.

Jorge, M. S. B., Diniz, A. M., Lima, L. L., \& Penha, J. C. (2015). Apoio matricial, projeto terapêutico singular e produção do cuidado em saúde mental. Texto \& ContextoEnfermagem, 24(1), 112-120. https://doi.org/10.1590/0104$\underline{07072015002430013}$

Lei $n^{\circ} 11.129$, de 30 de junho de 2005. (2005). Institui o Programa Nacional de Inclusão de Jovens - ProJovem; cria o Conselho Nacional da Juventude - CNJ e a Secretaria Nacional de Juventude; altera as Leis $\mathrm{n}^{\circ} \mathrm{s} 10.683$, de 28 de maio de 2003, e 10.429, de 24 de abril de 2002; e dá outras providências. Diário Oficial da União. Ministério da Saúde. http://www.planalto.gov.br/ccivil_03/_ato20042006/2005/lei//11129.htm

Ministério da Saúde. (2003). Saúde mental e atenção básica: o vínculo e o diálogo necessários. Secretaria de Atenção à Saúde. Departamento de ações programáticas estratégicas/departamento de atenção básica. Coordenação de Saúde Mental/Coordenação de Gestão de Atenção Básica. http://portal. saude.gov.br/portal/ arquivos/pdf/diretrizes.pdf

Ministério da Saúde. (2004). HumanizaSUS: equipe de referência e apoio matricial. Secretaria Executiva, Núcleo Técnico da Politica Nacional de Humanização. https://bvsms.saude. gov.br/bvs/publicacoes/equipe_referencia.pdf
Ministério da Saúde. (2005). Reforma psiquiátrica e política de saúde mental no Brasil. Secretaria de Atenção à Saúde. Secretaria de Atenção à Saúde. DAPE. Coordenação Geral de Saúde Mental. https://bvsms.saude.gov.br/bvs/ publicacoes/Relatorio15_anos_Caracas.pdf

Ministério da Saúde. (2009). Clínica ampliada e compartilhada. Secretaria de Atenção à Saúde. Política Nacional de Humanização da Atenção e Gestão do SUS. http:// bvsms.saude.gov.br/bvs/publicacoes/clinica ampliada compartilhada.pdf

Ministério da Saúde. (2010). Diretrizes do NASF: Núcleo de Apoio a Saúde da Família (Série A. Normas e Manuais Técnicos, Caderno de Atenção Básica, n. 27). Secretaria de Atenção à Saúde, Departamento de Atenção Básica. https://bvsms. saude.gov.br/bvs/publicacoes/diretrizes_do_nasf_nucleo. pdf

Ministério da Saúde. (2014). Núcleo de Apoio à Saúde da Família - Volume 1: Ferramentas para a gestão e para o trabalho (Cadernos de Atenção Básica, n. 39). Secretaria de Atenção à Saúde. Departamento de Atenção Básica. https://bvsms. saude.gov.br/bvs/publicacoes/nucleo_apoio_saude_ familia cab39.pdf

Nascimento, M. L., Manzini, J. M., \& Bocco, F. (2006). Reinventando as práticas psi. Psicologia \& Sociedade, 18(1), 15-20. https:// doi.org/10.1590/S0102-71822006000100003

Passos, E., \& Barros, R. B. (2000). A construção do plano da clínica e o conceito de transdisciplinaridade. Psicologia: teoria e pesquisa, 16(1), 71-79. https://doi.org/10.1590/S0102$\underline{37722000000100010}$

Pedrosa, S. P. O. F., \& Pereira, E. R. (2020). Coordenando grupos em sala de espera: analisando o processo. Revista da SPAGESP, 21(2), 66-82. http://pepsic. bvsalud.org/scielo.php?script=sci_arttext\&pid=\$167729702020000200006\&lng=pt\&tlng=pt

Resolução $n^{\circ} 287$, de 08 de outubro de 1998. (1998). Relaciona categorias profissionais de saúde de nível superior para fins de atuação do CNS. Diário Oficial da União. Ministério da Saúde. https://bvsms.saude.gov.br/bvs/saudelegis/ cns/1998/res0287 0810 1998.html 
Rossi, V. R. (2015). Medida de Segurança: a violação do direito à saúde a partir do conceito de periculosidade. Cadernos Ibero-americanos de Direito Sanitário, 4(3), 75-93. https:// doi.org/10.17566/ciads.v4i3.171

Silva, L. J. C. D. A., Araújo, A. C. V. D., Vasconcelos, N. L. D., Paiva, C. B. N., \& Pires, C. A. (2019). A Contribuição do apoiador matricial na superação do modelo psiquiátrico tradicional. Psicologia em Estudo, 24, e44107. https://doi.org/10.4025/ psicolestud.v24i0.44107
Tófoli, L. F., \& Fortes, S. (2007). Apoio matricial de saúde mental na atenção primária no município de Sobral, CE: o relato de uma experiência. SANARE-Revista de Políticas Públicas, 6(2), 34-42. https://sanare.emnuvens.com.br/sanare/article/ view/151/143 